\title{
CALCULATION OF POST-CLOSURE NATURAL CONVECTION HEAT AND MASS TRANSFER IN YUCCA MOUNTAN DRIFTS
}

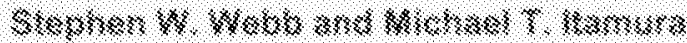

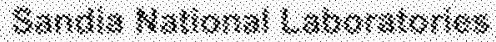 \\ A2:
}

\begin{abstract}
A

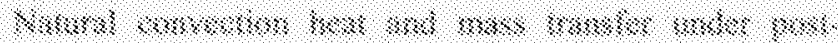

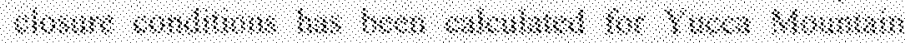

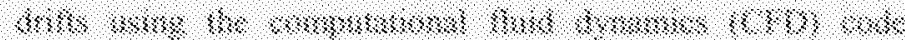

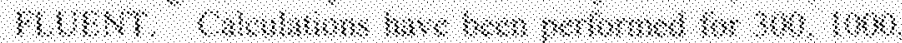

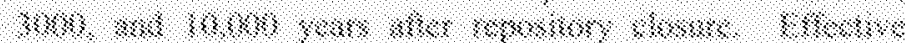

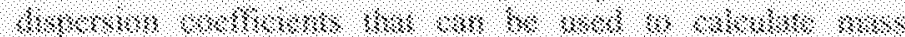

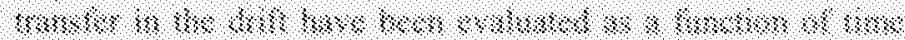

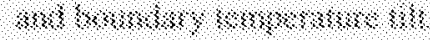

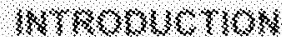

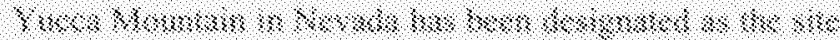

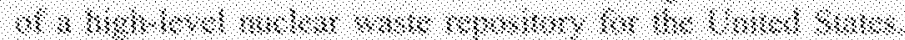

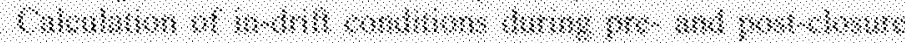

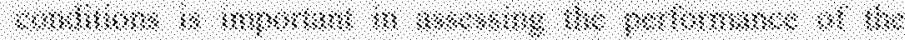

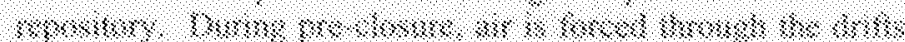

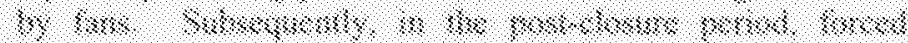

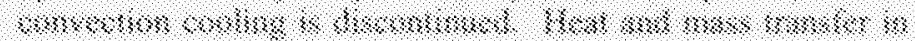

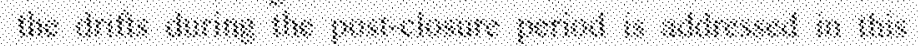
$\$ \$ \%$

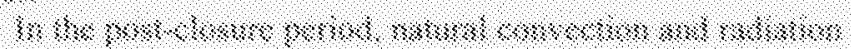

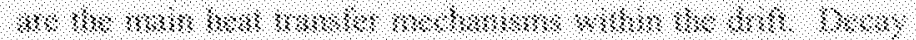

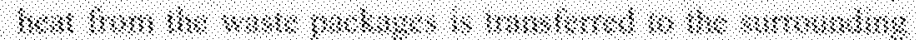

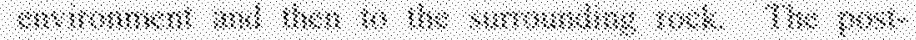

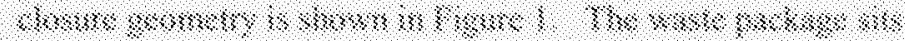

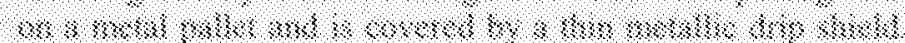

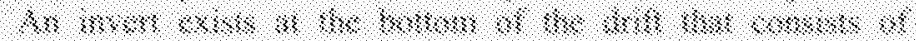

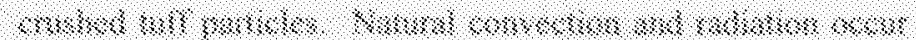

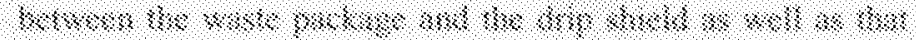

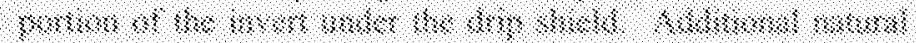

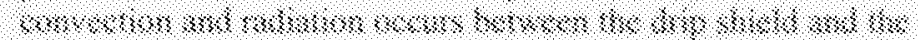

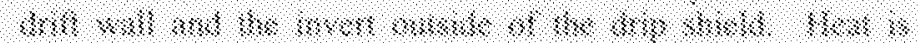

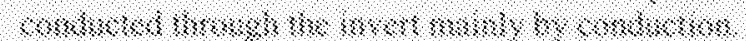

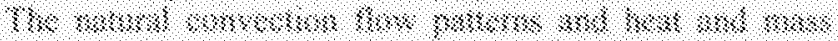

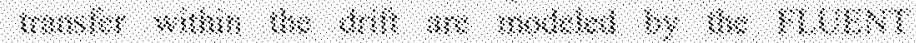

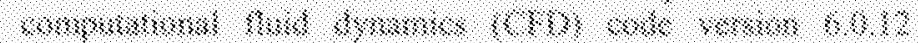

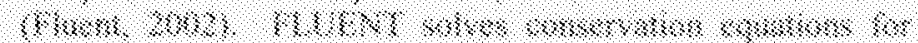

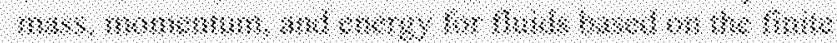

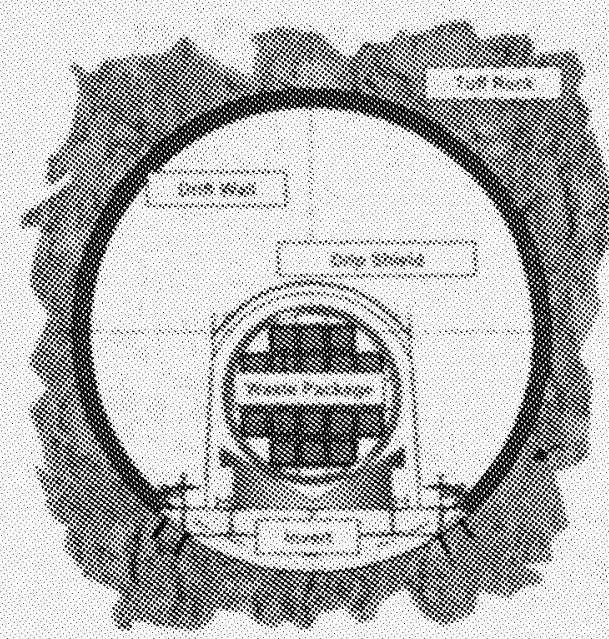

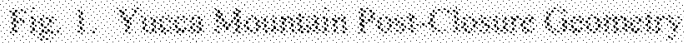

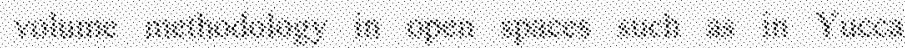

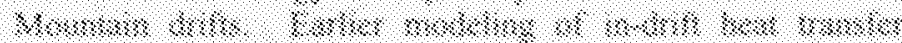

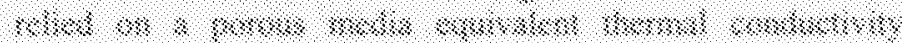

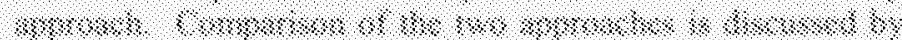

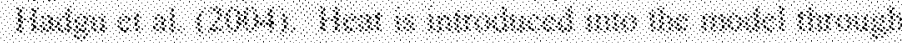

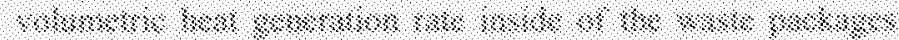

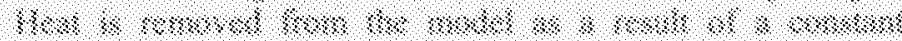

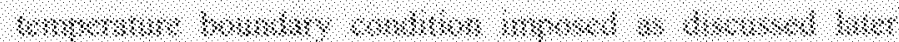

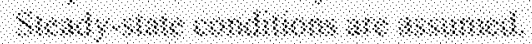

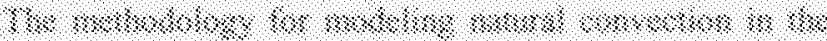
\$०⿱

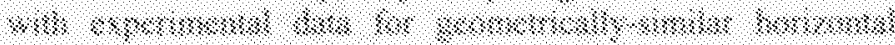

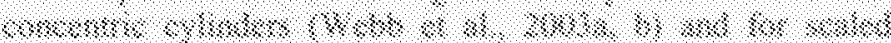

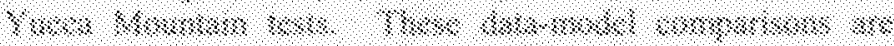

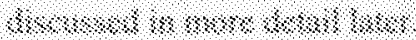

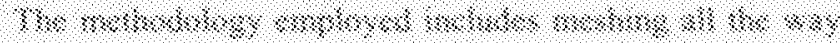

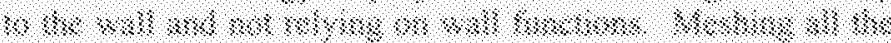

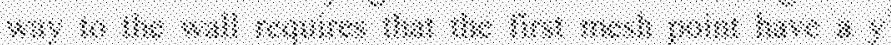


value of about 1.0, which leads to significant meshing requirements. $\mathrm{y}^{+}$is a dimensionless distance from the wall equal to the actual distance times the wall-friction velocity divided by the viscosity, or $y v^{*} / v$. Meshing all the way to the wall is necessary because the alternative of using wall functions is not appropriate. Wall functions are based on forced convection data and assume that the velocity profile is monotonic. In contrast, the velocity profile in natural convection has a velocity peak near the wall, so wall functions are not appropriate. The use of wall functions is also not appropriate when low-Reynolds number effects are pervasive within the flow domain or in the presence of strong body forces.

The RNG $k-\varepsilon$ two-equation turbulence model was selected for this analysis. The primary reasons for using the RNG $k-\varepsilon$ turbulence model are that it allows for variation in the turbulent Prandtl number as a function of flow conditions, it provides a means for including low-Reynolds number effects in the effective viscosity formulation, and it includes an extra term, $R_{\varepsilon}$, in the $\mathcal{E}$-equation to better model separated flows.

As mentioned above, internal natural convection using FLUENT and the above methodology has been validated by comparison to experimental data. The approach has been validated against literature data from Kuehn and Goldstein $(1976,1978)$ and others for the case of horizontal concentric cylinders in laminar and turbulent flow (Webb et al., 2003b). The FLUENT predictions agree very well with the available overall heat transfer experimental data for gap-width Rayleigh numbers up to $5 \times 10^{9}$. Three different turbulence models (Spalart-Allmaras, RNG k- $\varepsilon$, SST k- $\omega$ ) showed small differences $(\sim 10 \%)$ for the highest Rayleigh number, well within the experimental uncertainty. Local heat transfer data from Kuehn and Goldstein (1978) are available at a Rayleigh number of $2.51 \times 10^{6}$. However, as discussed by Webb et al. (2003b), these data are not adequate to distinguish between the various turbulence models.

The validation of the RNG turbulence model above is limited to the total heat transfer rate and surface temperatures. Experimental data for the horizontal annulus configuration are not available to validate the local heat transfer or the fluid velocities. In order to evaluate the appropriateness of the RNG turbulence model for natural convection, comparison to data for a differentially heated square enclosure has been performed as given by James and Webb (2004). Their results show that all of the two-equation turbulence models examined (standard $k-\varepsilon$, RNG k- $\varepsilon$, SST k- $\omega$ ) perform similarly to each other, and that none of the models performs particularly well in the prediction of detailed time-averaged mean quantities including velocity and temperature profiles. Therefore, while the RNG turbulence model is as good as the other engineering turbulence models investigated, there is a significant amount of uncertainty in the results.

The available experimental data used in the data-model comparisons discussed in the previous paragraphs are at small length scales (gap width $\sim 3 \mathrm{~cm}$ ) compared to the Yucca Mountain geometry (gap width $\sim 1.9 \mathrm{~m}$ ). Therefore, much larger scale tests were conducted. These length scales are at $25 \%$ and $44 \%$ of full-scale Yucca Mountain drifts. Temperature data-model comparisons show very good agreement between FLUENT and the experimental temperature data as discussed in detail by Dalvit-Dunn et al., (2004).
Velocity data-model comparisons were reasonable with significant uncertainty in the experimental data.

Thermal radiation is very important in the present application, accounting for about $75-80 \%$ of the total heat transfer between the waste package and the drift walls. Thermal radiation heat transfer modeled by the discrete ordinates (DO) approach. The DO model solves the radiative transfer equation for a finite number of discrete solid angles. The DO model allows one to solve surface-to-surface radiation and fluid participation radiation. This model is restricted to either gray or non-gray thermal radiation using a banded gray model. The radiative transfer equation accounts for scattering, gas emission, and absorption. The surfaces are treated as gray, diffuse surfaces.

In addition to the heat transfer calculations and fluid velocities, the FLUENT model has also been used to calculate mass dispersion coefficients within the drift due to natural convection flow patterns. These dispersion coefficients are needed for mass transfer within a drift including the transport of water vapor and trace chemicals.

\section{NOMENCLATURE}

$\begin{array}{ll}\text { A } & \text { cross sectional area }\left(\mathrm{m}^{2}\right) \\ \text { C } & \text { concentration } \\ \text { D } & \text { effective dispersion coefficient }\left(\mathrm{m}^{2} / \mathrm{s}\right) \\ \text { L } & \text { length }(\mathrm{m}) \\ Q & \text { mass flow rate }(\mathrm{kg} / \mathrm{s}) \\ \rho & \text { fluid density }\left(\mathrm{kg} / \mathrm{m}^{3}\right)\end{array}$

\section{NUMERICAL MODEL}

The physical subsystem to be modeled is the region inside of the emplacement drifts as shown earlier in Figure 1. Heat is generated inside of the waste canisters due to the decay of the radioactive materials, which decreases with time. The waste packages are to be emplaced on metal pallets with a small axial gap between packages. The waste packages vary in length and diameter depending on the type of waste in the container. The pallets sit on top of a crushed tuff invert. A thin metallic drip shield covers the waste packages. The emplacement drifts are drilled at regularly spaced intervals into the host rock. The host rock, invert, waste packages, and drip shield are all physically represented in the natural convection models.

After emplacement of the waste, the drift will be ventilated for a period of up to 50 years, which will remove a large fraction of the waste heat as well as some moisture from the drift. The amount of time that a drift is ventilated will vary depending on when the drift is loaded and when the repository is finally closed. At closure, the drip shield is installed to cover the waste packages. The natural convection model is run at specific times after closure of the repository. The linkage of the natural convection models to the environment is through the boundary conditions of the model. The rock temperature five meters into the host rock from the drift wall is used as a radially constant temperature boundary condition for the natural convection models because the effects of in-drift geometry are small at that distance into the rock (BSC, 2001). The rock temperature at this location is calculated from line-source analytical solutions. Initial conditions for the natural convection models are not needed because the constant 


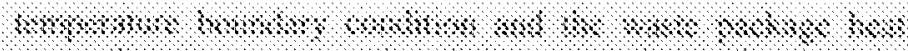

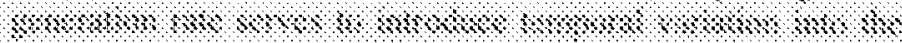

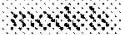

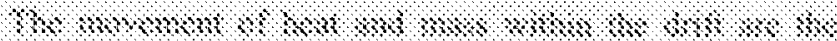

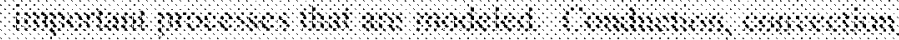

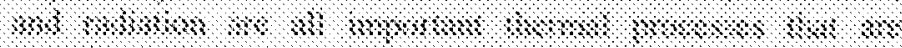

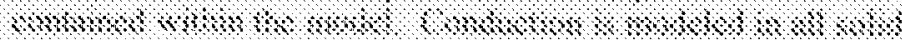

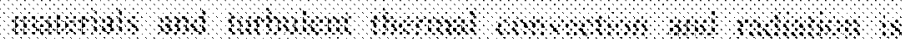

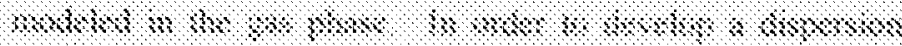

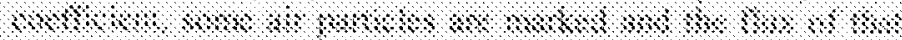

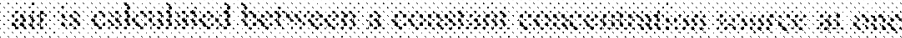

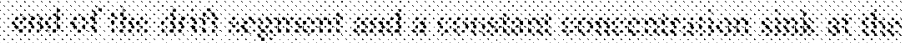
$3+\$, \$$

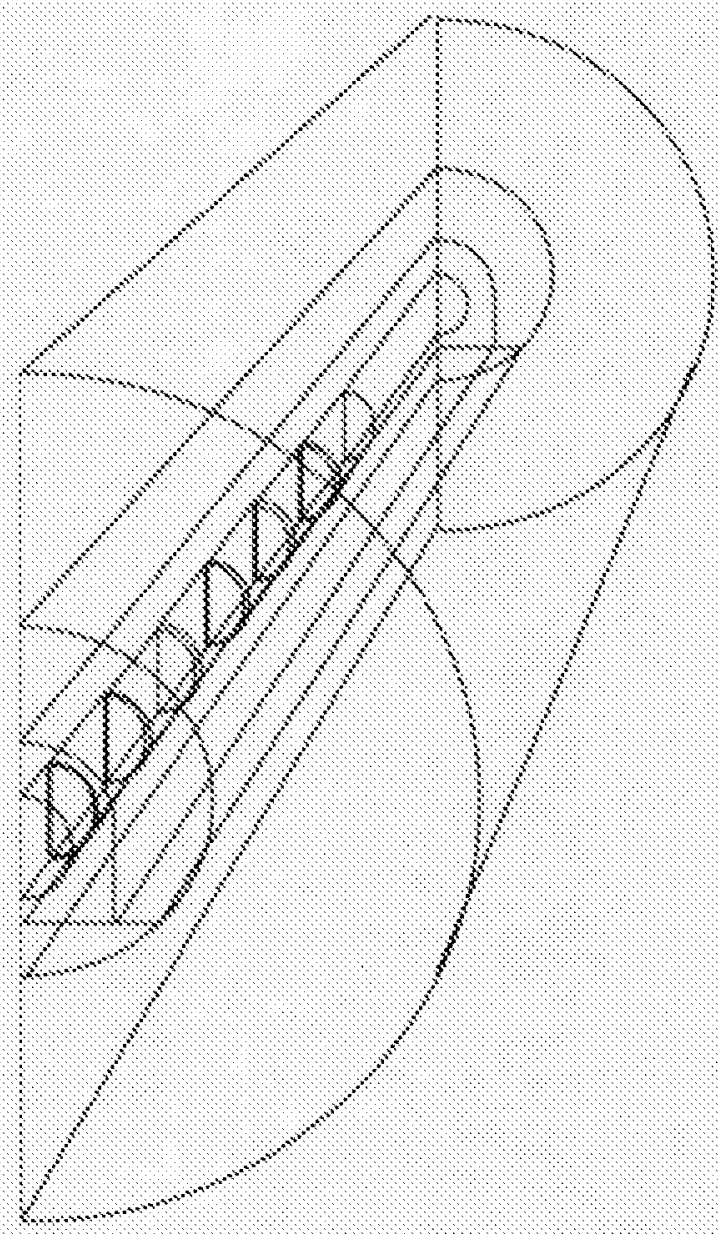

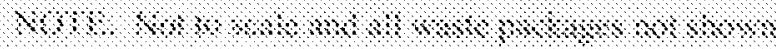

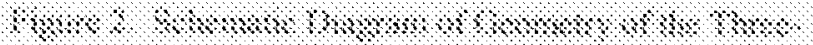

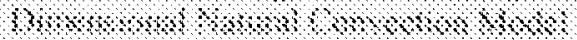

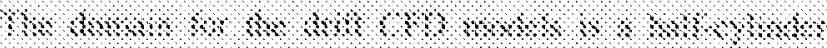

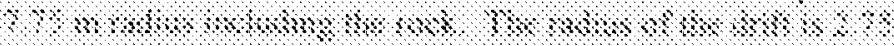

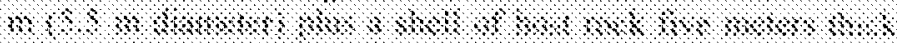

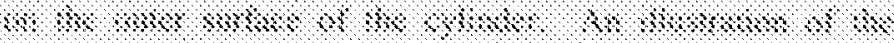

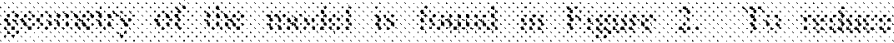

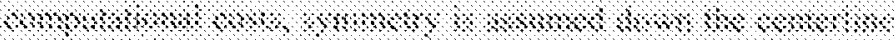
$, 3,8 \mathrm{~m}$

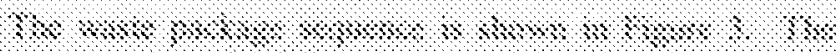

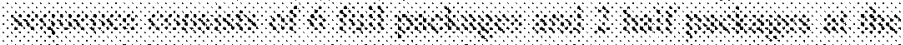

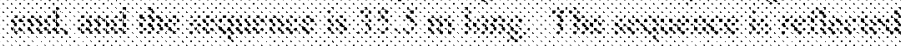

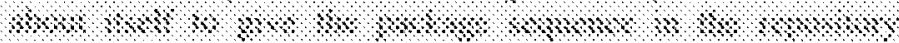

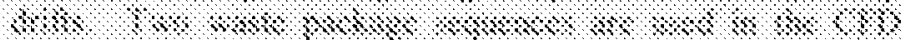

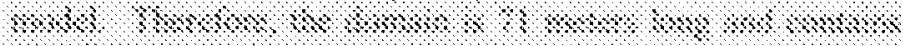

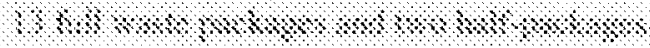
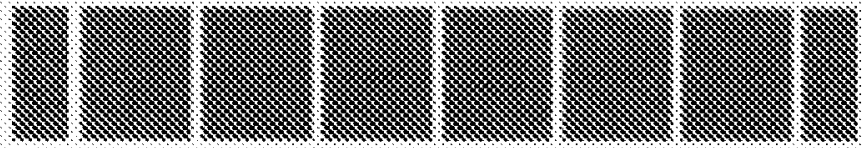

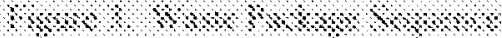

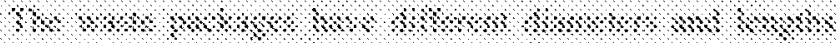

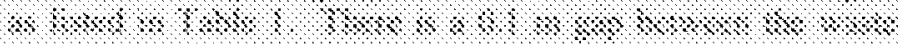

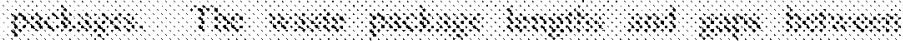

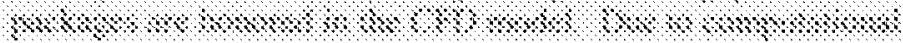

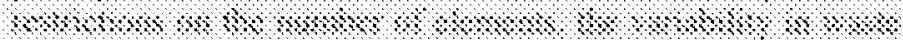

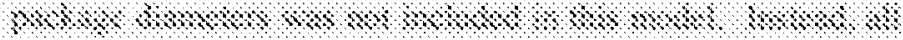

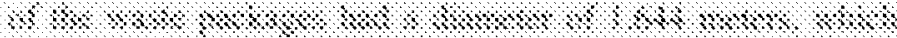

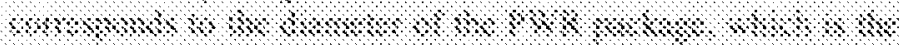

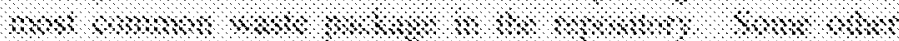

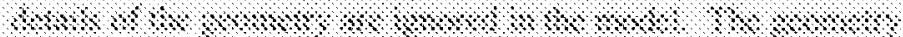

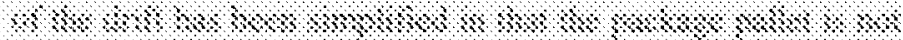

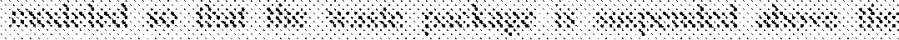

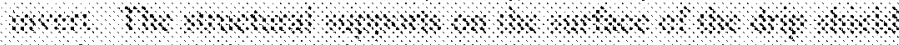

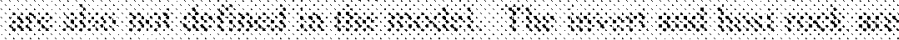

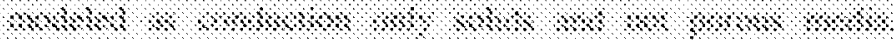

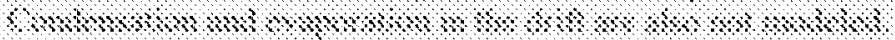

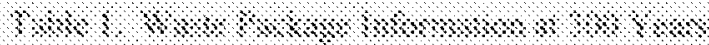

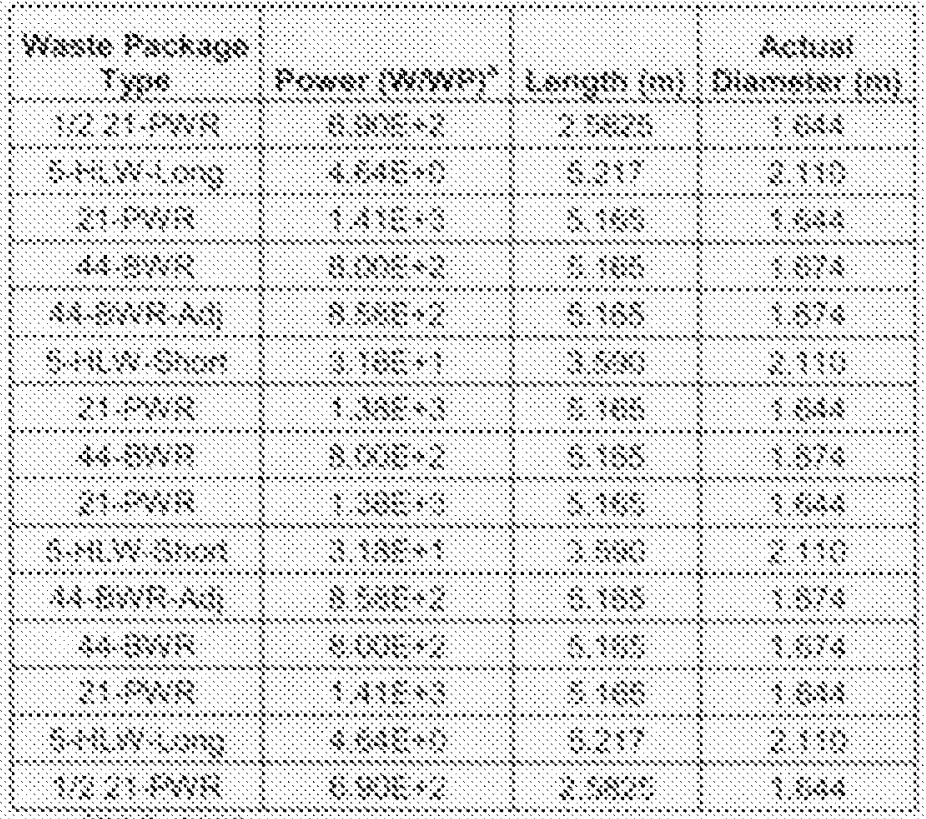

$3+3$ 


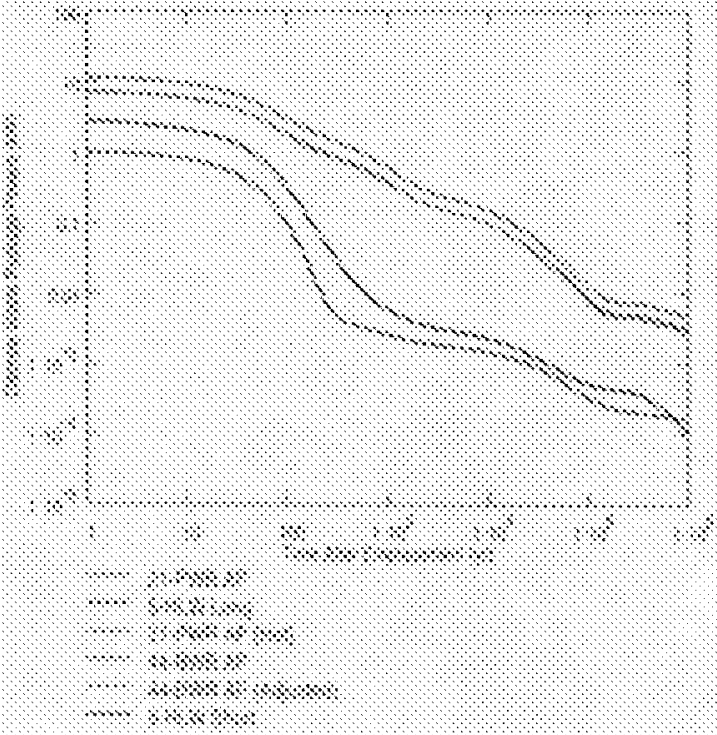

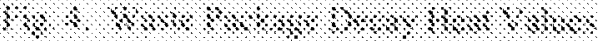

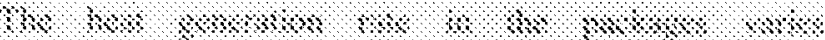

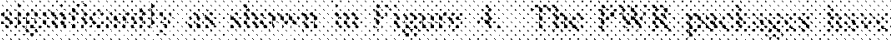

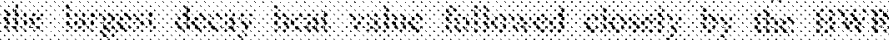

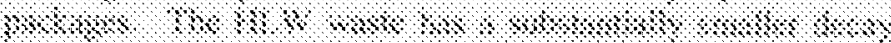
$\$, 3,4,3,1,+3,1,3$

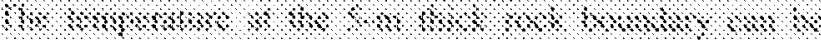

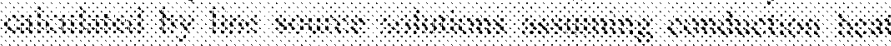

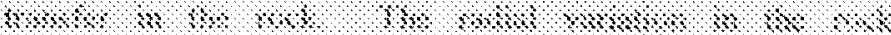

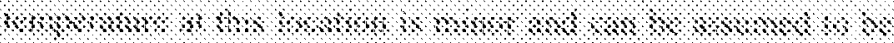

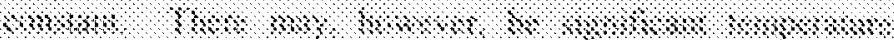

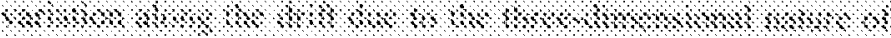

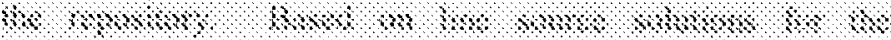

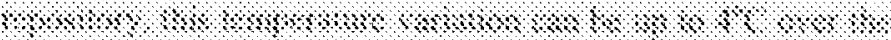

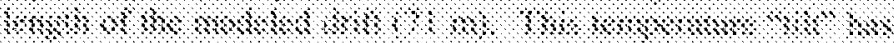

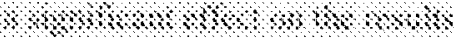

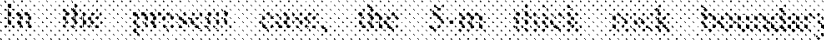

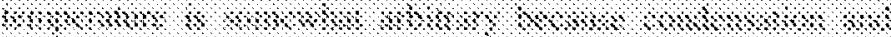

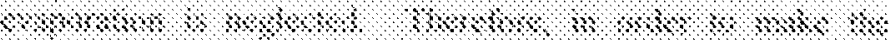

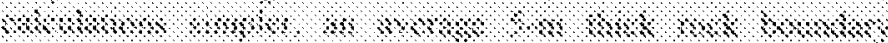

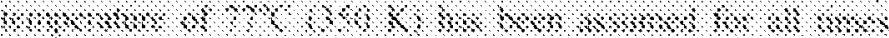

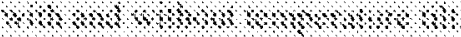

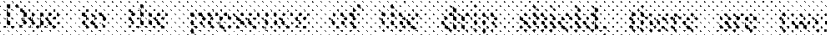

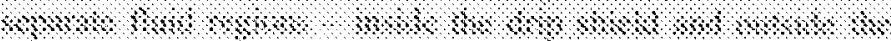

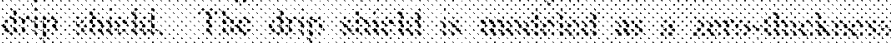

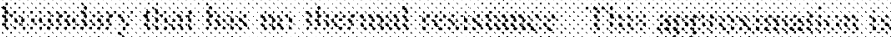

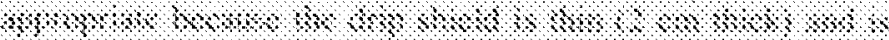

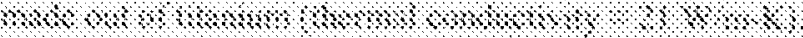

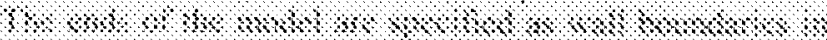

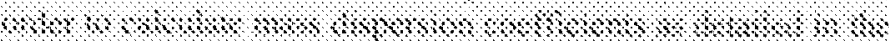

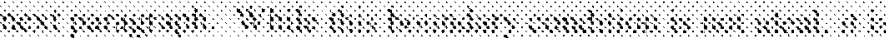

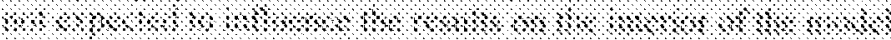

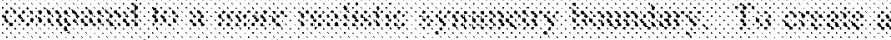

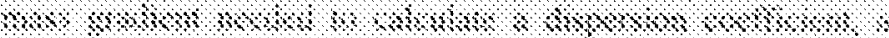

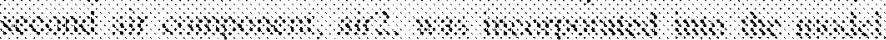

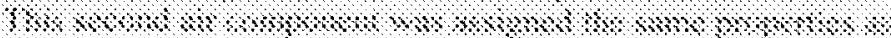
no

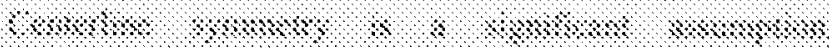

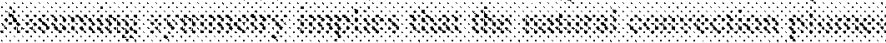

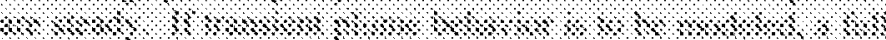

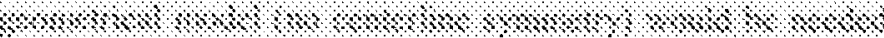

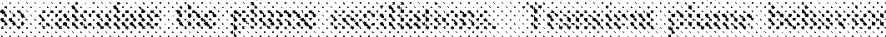

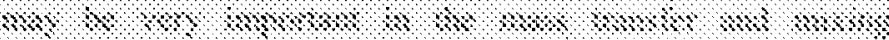
\$

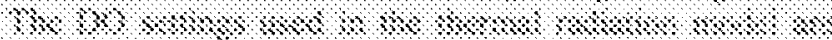

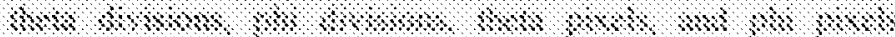

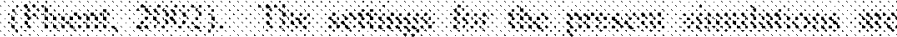

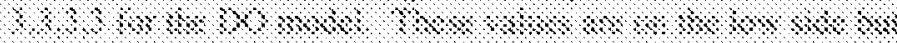

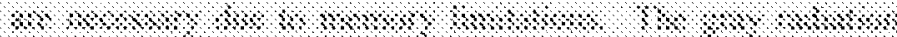

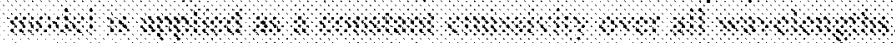

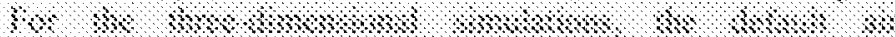

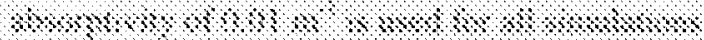

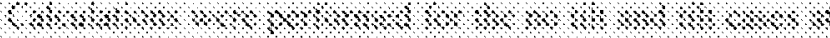

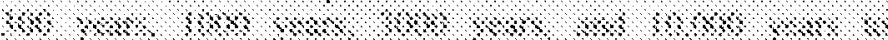

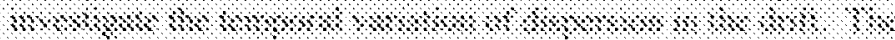

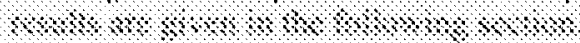

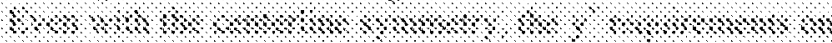

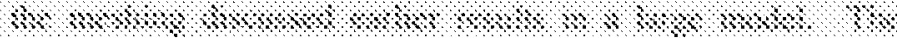

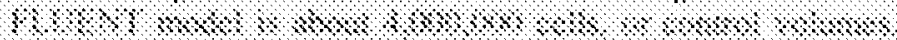

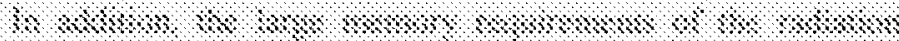

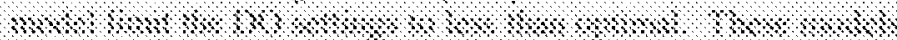

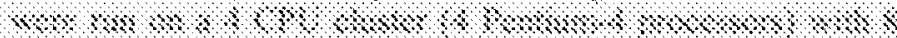

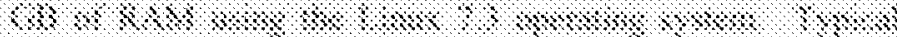

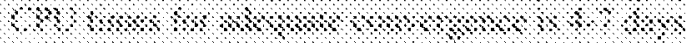

\section{NEOH:}

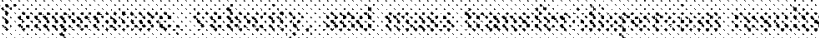

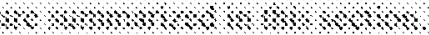

\section{$1,3,3,3$}

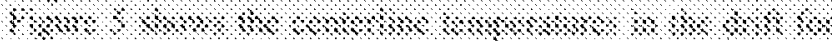

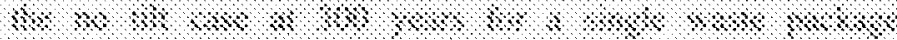

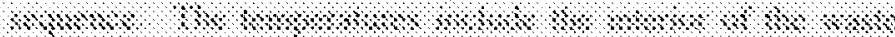

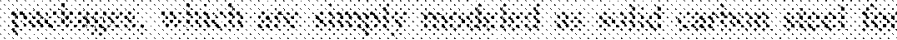

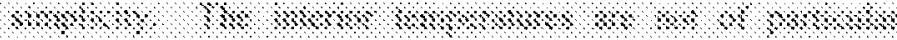

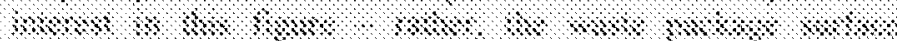

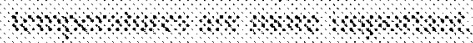

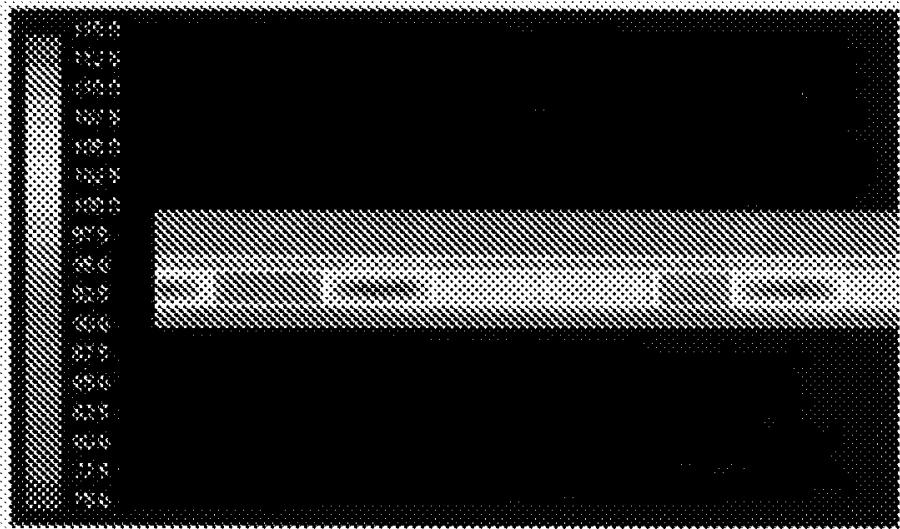

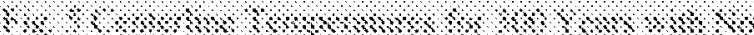
\$n, 1, 


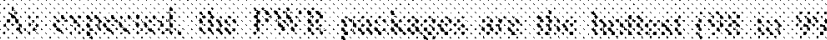

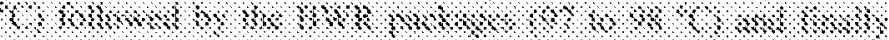

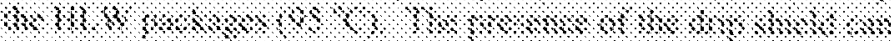
\$

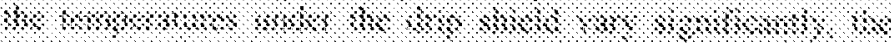

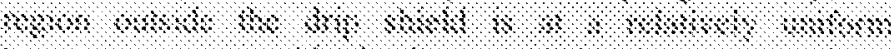

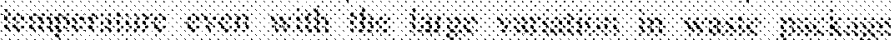

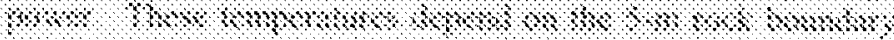

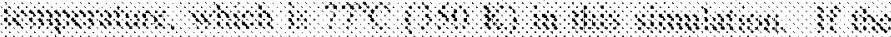

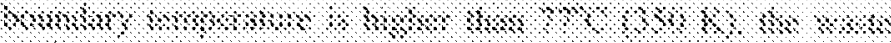

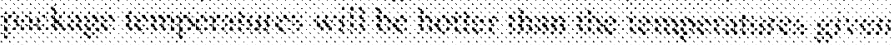
16\%k

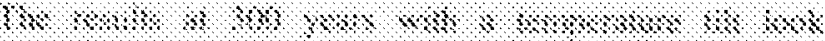

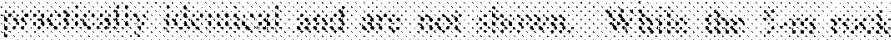

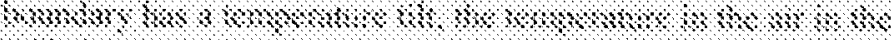

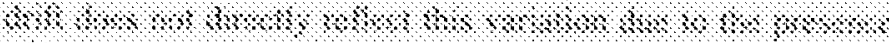

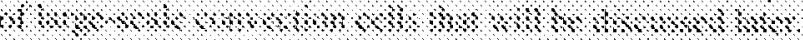

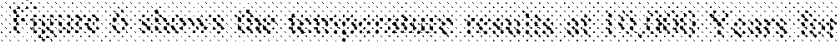

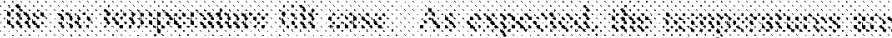

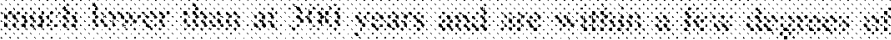

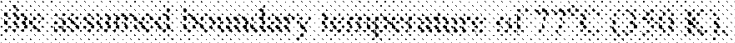

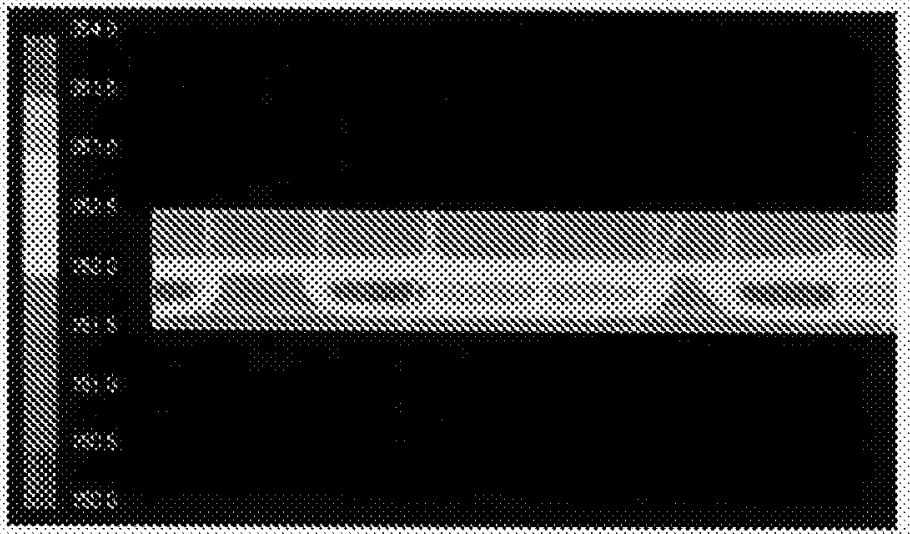

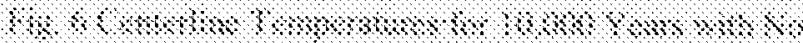

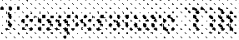

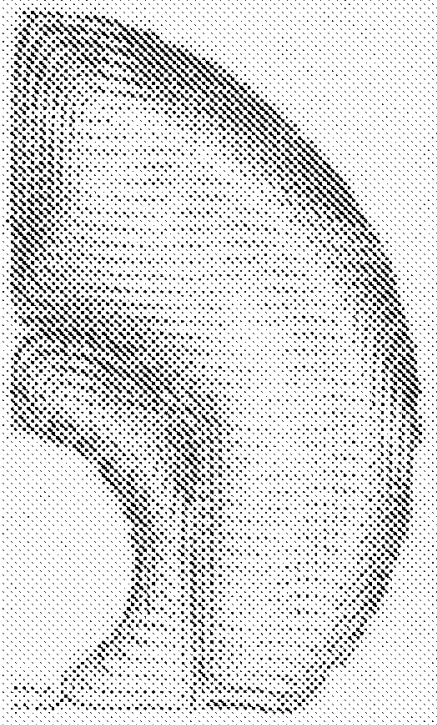

sisks

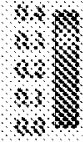

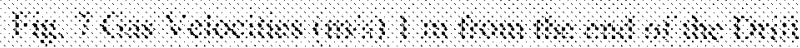

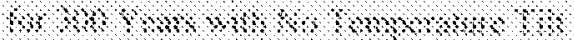

\section{$3,100 \% 10$}

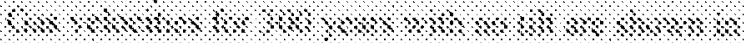
४०००

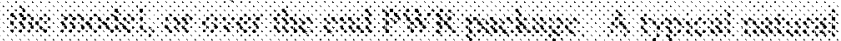

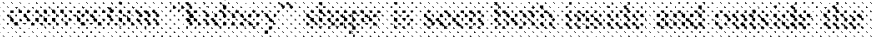

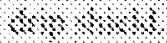

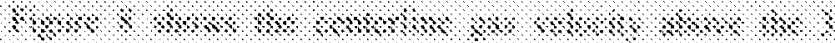

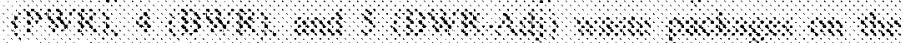

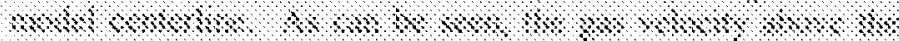

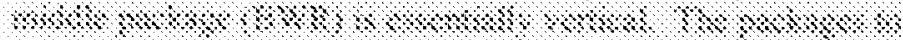

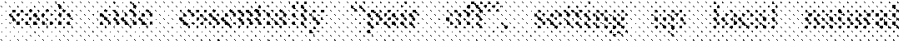

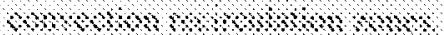

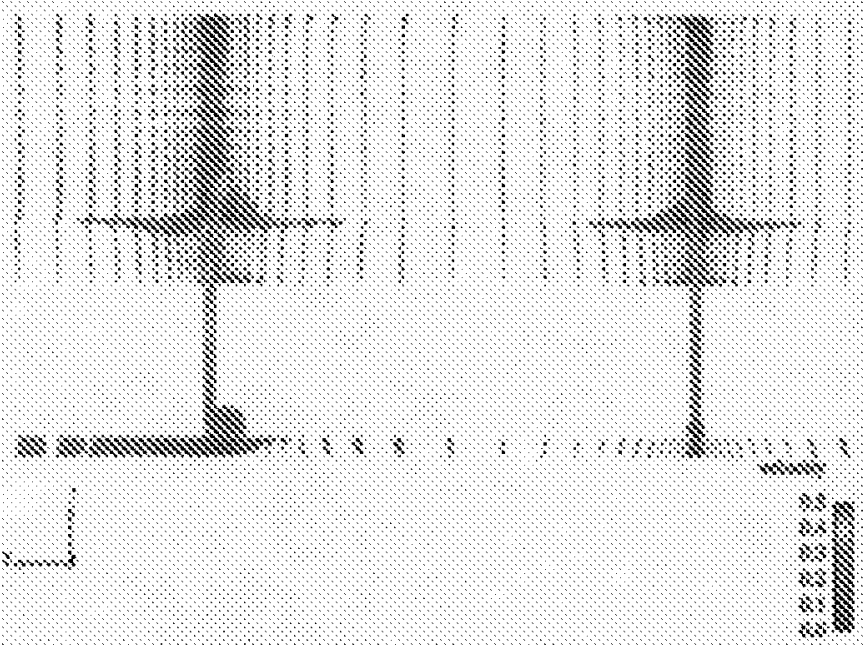

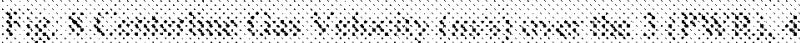

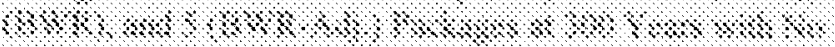

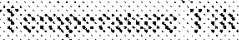

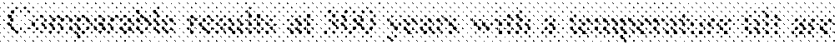

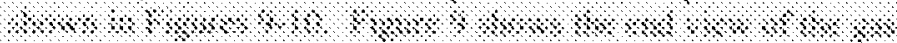

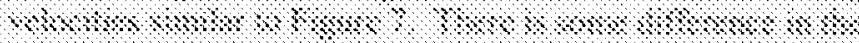

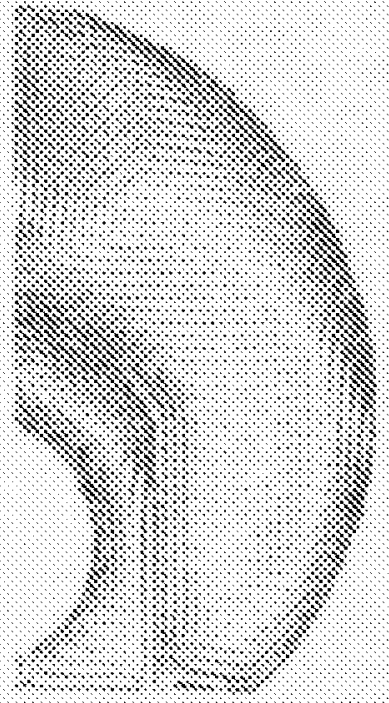

38

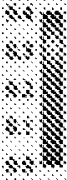

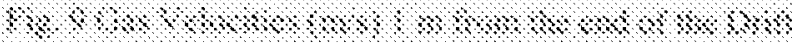

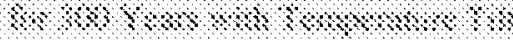




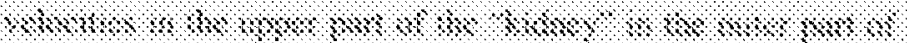

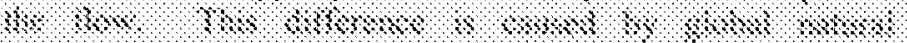

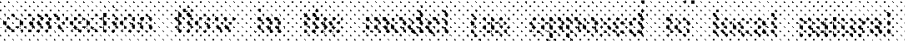

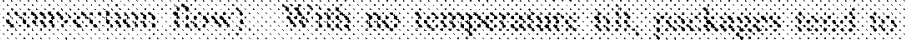

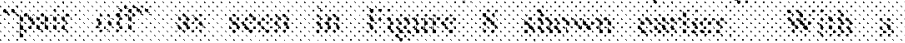

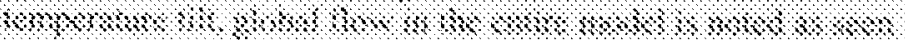

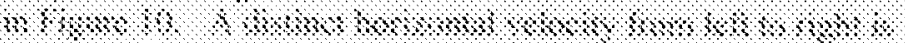

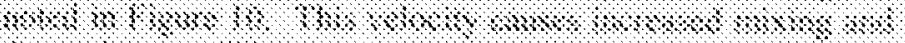

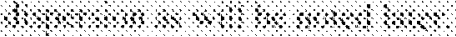

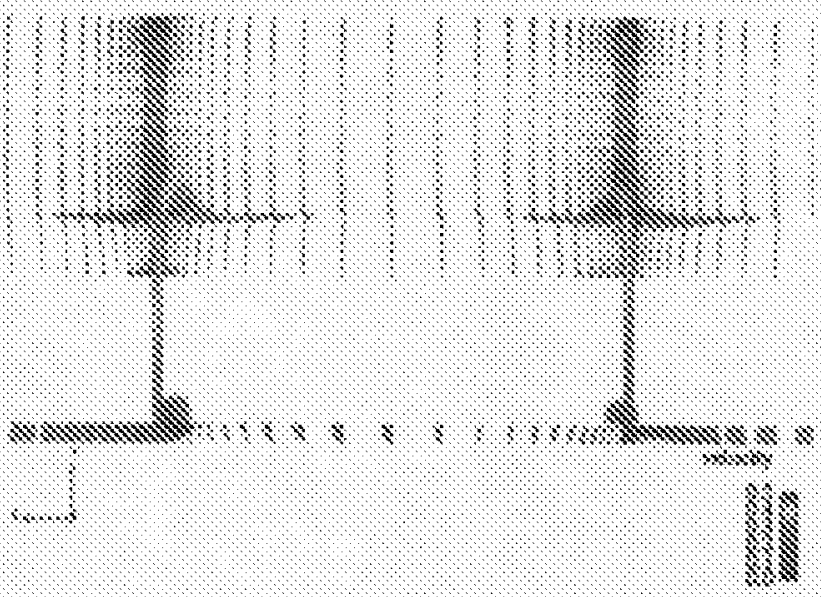

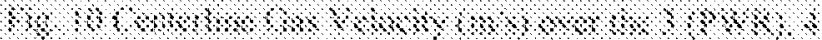

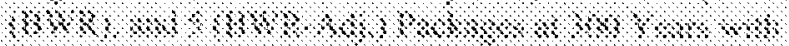
$3,3,3,3$

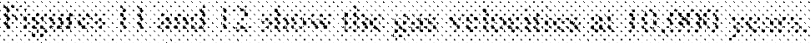

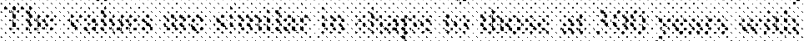

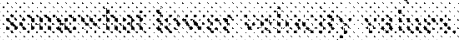
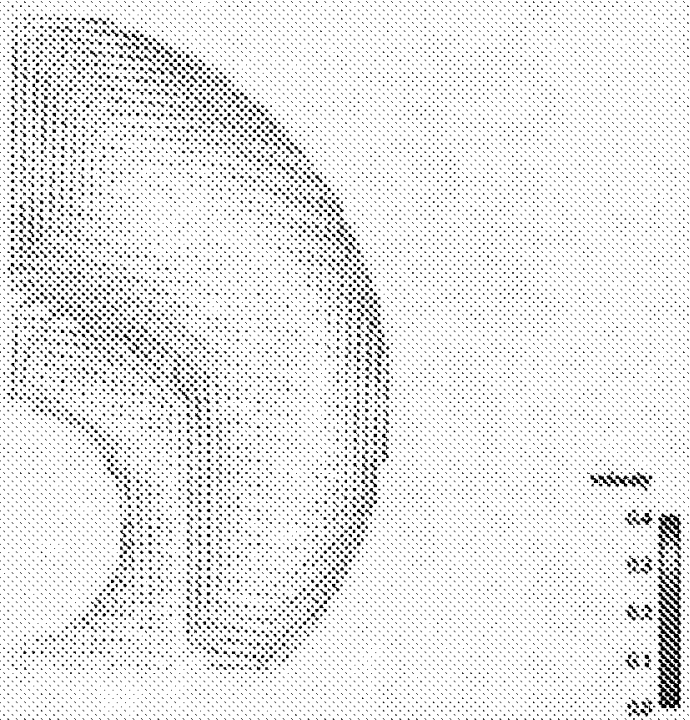

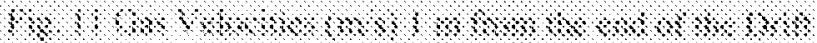
\$ $\$, \$, \$, \$, \$, \$, \$$

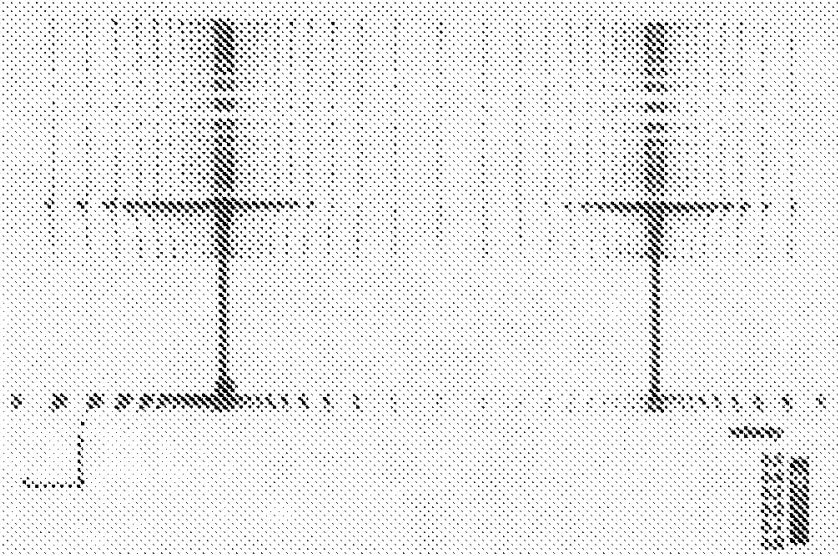

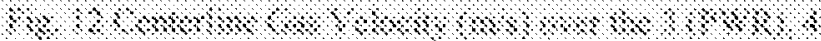

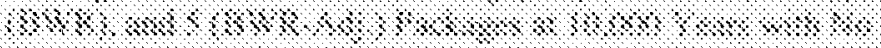
$3+3,3$

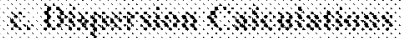

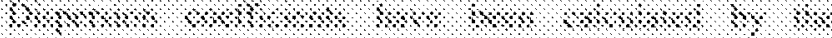

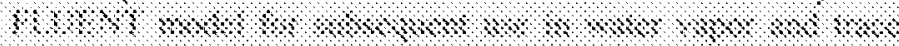

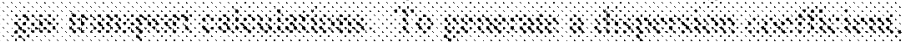

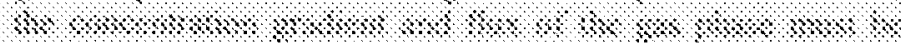

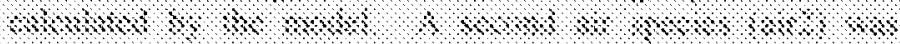

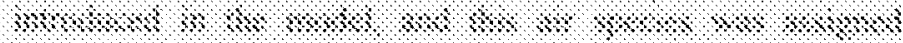


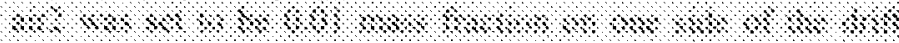

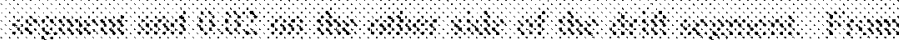

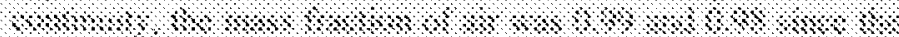

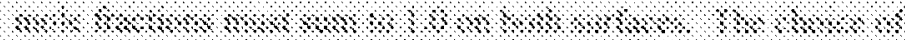

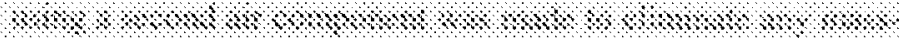
$3,13,3+3$

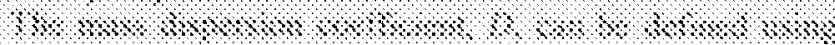
$3,3,3,3,3$,

$$
\text { + }+ \text { + }
$$

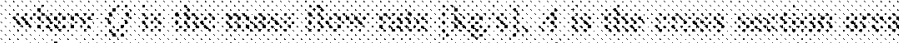
\$

\$ $\$+\$,+3$

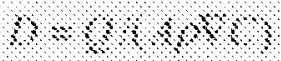

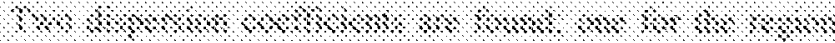

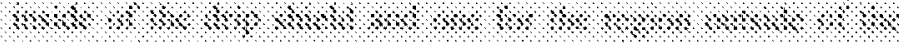

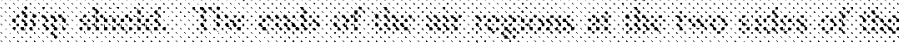

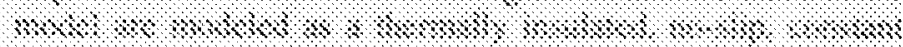

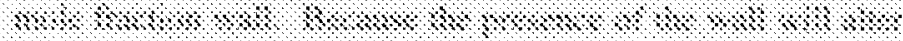

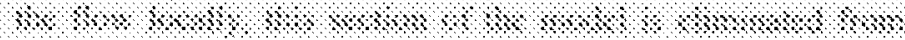

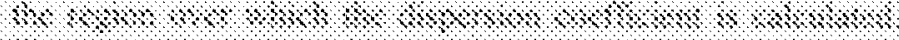

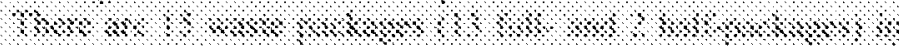

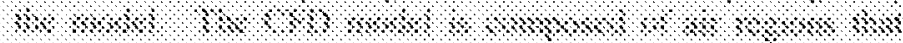

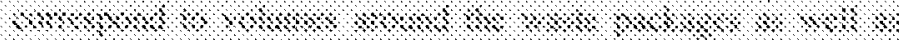

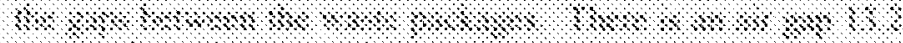

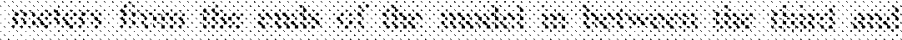

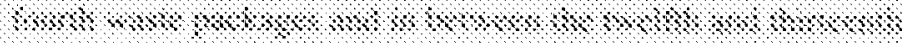

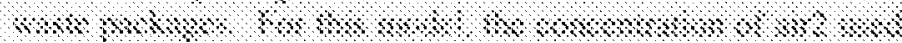


The simulation results are shown in Table 3 . The dispersion coefficients are higher for these cases than for the uniform temperature cases. The inner dispersion coefficients ranged from 0.007 to $0.01 \mathrm{~m}^{2} / \mathrm{s}$ while the outer dispersion coefficients ranged from 0.03 to $0.1 \mathrm{~m}^{2} / \mathrm{s}$, or up to 5000 times molecular. The inner values are slightly higher when compared with the previous simulations. The outer values are several orders of magnitude higher than for the uniform temperature case. Figure 10 given earlier shows the presence of global recirculation in the presence of temperature tilt, which leads to the significantly higher dispersion coefficient with temperature tilt compared to no tilt.

Table 3 Dispersion Coefficients $\left(\mathrm{m}^{2} / \mathrm{s}\right)$ With Temperature Tilt

\begin{tabular}{|l|c|c|c|c|}
\hline & 300 & 1000 & 3000 & 10,000 \\
Yrs & Yrs & Yrs & Yrs \\
\hline Under Drip Shield & 0.007 & 0.007 & 0.009 & 0.01 \\
\hline Outside Drip Shield & 0.1 & 0.1 & 0.1 & 0.03 \\
\hline
\end{tabular}

\section{SUMMARY AND CONCLUSIONS}

FLUENT has been used to model the heat and mass transfer in Yucca Mountain Drifts during the post-closure period. There are significant differences in the waste package power at various times that leads to significant differences in waste package temperatures.

General natural circulation flow patterns are observed in the cross section. With no temperature tilt, the packages mostly "pair off" setting up local natural convection cells axially. When temperature tilt is added, larger scale convection cells are established.

The calculation of effective mass dispersion coefficients has been performed for various times with and without temperature tilt. The effective dispersion coefficients are from several hundred to several thousand times the molecular value. The value for the area under the drip shield is not significantly affected by time or the temperature tilt. The outer region dispersion coefficient is not a strong function of time, but it is significantly affected by the temperature tilt.

\section{ACKNOWLEDGMENTS}

This work was supported by the Office of Repository Development as part of the Civilian Radioactive Waste Program, which is part the US Department of Energy. Sandia is a multiprogram laboratory operated by Sandia Corporation, a Lockheed Martin Company, for the United States Department of Energy's National Nuclear Security Administration under contract DE-AC04-94AL85000.

\section{REFERENCES}

BSC (Bechtel SAIC Company) 2001. Repository Multiple Waste Package Thermal Calculation. CAL-WIS-TH-000010 REV 00. Las Vegas, Nevada: Bechtel SAIC Company.

BSC (Bechtel SAIC Company) 2003. Repository Design Project, RDP/PA IED Typical Waste Package Components Assembly (3). 800-IED-WIS0-00203-000-00A. Las Vegas, Nevada: Bechtel SAIC Company.

Dalvit-Dunn, S., S.W. Webb, N.D. Francis, Jr., M.T. Itamura, and J. Del Mar, 2004, "Comparison of CFD Calculations with Experimental Results for the YMP Scaled Natural Convection Tests," HT-FED2004-56409, 2004 ASME Heat Transfer/Fluids Engineering Summer Conference, Charlotte, NC, July 11-15, 2004.

FLUENT 6 User's Guide, 2002, Fluent Inc., Lebanon, NH.

Hadgu, T., S.W. Webb, M.T. Itamura, and N.D. Francis,

Jr., 2004, "Comparison of CFD Natural Convection and Conduction-only Models for Heat Transfer in the Yucca Mountain Project Drifts," HT-FED2004-56085, 2004 ASME Heat Transfer/Fluids Engineering . Summer Conference, Charlotte, NC, July 11-15, 2004.

James, D.L., and S.W. Webb, 2004, "Performance Evaluation of Turbulence Models in a Two-Dimensional Square Enclosure," HT-FED2004-56085, 2004 ASME Heat Transfer/Fluids Engineering Summer Conference, Charlotte, NC, July 11-15, 2004.

Kuehn, T.H., and Goldstein, R.J., 1976, "Correlating Equations for Natural Convection Heat Transfer Between Horizontal Circular Cylinders," Int. J. Heat Mass Transfer, 19:1127-1134.

Kuehn, T.H., and Goldstein, R.J., 1978, “An Experimental Study of Natural Convection Heat Transfer in Concentric and Eccentric Horizontal Cylindrical Annuli," Journal of Heat Transfer, 100:635-640.

Pruess, K., 1987, TOUGH User's Guide, Lawrence Berkeley National Laboratory.

Webb, S.W., N.D. Francis, S. Dalvit-Dunn, M.T. Itamura, and D.L. James, 2003a, "Thermally-Induced Natural Convection Effects in Yucca Mountain Drifts," J. Contam. Hydrol., 62-63:713-730.

Webb, S.W., N.D. Francis, M.T. Itamura, and D.L. James, 2003b, "CFD Calculation of Internal Natural Convection in the Annulus Between Horizontal Concentric Cylinders," ASME Paper HT2003-47515, 2003 ASME Summer Heat Transfer Conference, Las Vegas, NV, July 21-23, 2003. 